\title{
COMPARING STUDENT BEHAVIORS AND SCHOOL SATISFACTION BETWEEN STUDENTS WITH AUTISM SPECTRUM DISORDER AND TYPICALLY DEVELOPING PEERS
}

\author{
Gianna DeToro, \\ Catherine Knowlden, \\ Karen H. Larwin ${ }^{i}$ \\ Youngstown State University, \\ USA
}

\begin{abstract}
:
School satisfaction for families of students with autism is a well-researched area. However, research comparing levels of school satisfaction and the number of behavioral incidences between students with autism and typically developing peers is imperative to ascertain the effectiveness of behavioral interventions and how they relate to school satisfaction. This study seeks to answer two questions: (1) Is there a difference in the number of behavior problems for students with autism compared to typically developing peers, and (2) Is there a difference in school satisfaction and satisfaction with discipline for students with autism compared to typically developing peers? Using data from the NCES National Household Education Surveys Program of 2016 Our Children's Future: A Survey of Young Children's Care and Education study, statistical analyses showed that there were significant differences between the number of times contacted about behavior problems for students with behavior problems and typically developing peers. However, there were no significant differences in levels of school satisfaction or satisfaction of discipline for students with autism compared to typically developing peers.
\end{abstract}

Keywords: special needs, autism, behavior, satisfaction

\section{Literature Review}

Behavioral interventions and school satisfaction for students and families of students with autism are topics that have been extensively researched. The purpose of this literature review is to examine the outcomes of these behavioral interventions in relation to reported school satisfaction in terms of addressing behaviors for this population in comparison to typically developing peers. The reason for analyzing this type of research is to determine if there are differences in parental satisfaction in terms of schools dealing

i Correspondence: email khlarwin@gmail.com 
with student behaviors between students with autism and typically developing peers in grades 3-5.

While there is an extensive amount of research on behavioral interventions for students with autism and on school satisfaction, the research included in this review will focus on the number of behavioral incidences and reported school satisfaction of parents of students on the autism spectrum as opposed to specific behavioral interventions and academic outcomes. The purpose of excluding this information is to be able to specifically compare behavioral incidences and satisfaction of schools handling behavioral incidences between students with autism and neurotypical peers.

\section{Behavior}

Many studies have been completed regarding behavioral problems observed in students with autism. Behavioral issues are very prevalent in students with autism compared to typically developing peers. Additionally, research has been conducted on satisfaction with school support for both students with autism and typically developing peers. Studies are available in both areas respectively but there are very few that link these two areas together. The current study will more closely examine the link between behavioral referrals and school support for students with autism and typically developing peers.

Students with autism typically experience behavioral difficulties in school. According to Munkhaugen et al. (2019), school refusal behavior is one example of behavioral issues observed in students with autism. Behaviors related to school refusal include deficits in problem-solving skills, responding, initiating activities, and decreased social motivation. A study by Ashburner et al. (2010), compared teacher perceptions of typically developing peers and students with autism in relation to the regulation of emotions and behaviors in a mainstream classroom setting. According to the teacher ratings, students with autism were rated at a significantly higher level compared to typically developing peers for displaying emotional and behavioral issues. These teachers also indicated that students with autism have more difficulty regulating their behaviors and emotions than typically developing peers in the mainstream classroom. Boonen et al. (2014), maintains that due to behavioral issues typically seen in students with autism, these students are at an increased risk for negative outcomes in the classroom. Based on the results of a questionnaire study by Boonen et al. (2014), the biggest predictor of externalizing behavior problems were the co-occurrence of the student's age and pragmatic language problems. With the focus on mainstreaming students into inclusive classrooms, behavior issues for students with autism have become a bigger concern. According to Strain et al. (2011), behavior problems are one of the most common reasons students with autism get excluded from the inclusive classroom. Behavioral problems can also include, aggressive behaviors, tantrums, and noncompliance in the classroom (Strain et al., 2011). 


\section{School Satisfaction}

Parents and caregivers of students with and without autism have reported ways to improve their satisfaction with the schools that their students are attending, emphasizing the importance of communication. Slade et al. (2018) conducted research on school satisfaction for families of students with autism. Their research focused on four areas: services provided, the content of the IEP document, the perceived level of agreement between the IEP document and the services provided, and the effectiveness of the IEP team. $61 \%$ of the participants were dissatisfied with at least one of these areas. Whitaker (2007) researched parental perceptions of school experiences for children with autism and also found that there were also levels of dissatisfaction in specific areas, specifically in the areas of promoting social development and social relationships, and listed school communication as a high priority. Starr and Foy (2012) found after surveying 144 parents of children with autism that common themes amongst participants were managing children's behavior, effective communication, and teachers' understanding of the disability were of highest importance. Zablotsky et al. (2012) analyzed a national sample of families from the 2007 Parent and Family Involvement in Education Survey and found that parents of children with autism were more likely to be unhappy with the level of communication provided by the school, and that there was a large positive correlation between school satisfaction and parental school involvement.

The literature reviewed regarding school satisfaction provides common themes regarding parents' perceptions of their schools' effectiveness when dealing with children with autism as well as student behavior. Overall, communication and behavior play a role in these perceptions. The research provided in this literature review allows for insight into how student behavior and school satisfaction for families of students with autism and neurotypical peers differ from one another.

Research has shown that school satisfaction and student behavior for students with autism typically go together. Students with autism need direct instruction and intensive behavioral supports to learn appropriate behaviors. Oftentimes, this means that schools need to have partnerships with parents to develop these behavioral interventions and to implement them at home to generalize newly taught replacement behaviors. The research analyzed in this literature review has shown that levels of school satisfaction in terms of communication and addressing student needs show significant room for improvement. Unfortunately, the existing gaps in research are on school satisfaction for neurotypical students and their families in these specific areas. Implications for further research should focus on the differences between students with autism and typically developing peers in terms of student behavior and school satisfaction, which will be the focus of our research. 


\section{Methods}

\subsection{Participants}

The participants analyzed for this study were selected from the NCES National Household Education Surveys Program of 2016 Our Children's Future: A Survey of Young Children's Care and Education study. Parents of the students studied were given this survey to complete regarding a multitude of factors. The total sample size consisted of 14,075 children, but 141 students were analyzed for this study to analyze how school satisfaction was reported for students with and without autism. The sample sizes vary depending on specific variables due to missing information. Descriptive statistics of times contacted about behavior problems are listed in the tables below (see Table 1), in addition to the total income, gender, grade range, and race and ethnicity of the participants (see Table 2).

\subsection{Instrumentation}

Many variables from the survey were selected and analyzed for this study. Basic demographic variables were selected including gender, race, income, and grade level. Only students in grades three to five were selected for this study. Students with autism and typically developing peers were also included. The number of behavior referrals variable was also included. School satisfaction variables were analyzed including satisfaction with discipline and satisfaction with schools. SPSS was used to analyze frequencies and differences between students with autism and typically developing peers using the variables discussed above.

\subsection{Procedures}

Bias was reduced by using concise survey questions that limited confusion. Additionally, the sample size was limited to grades 3-5 to reduce other factors that could contribute to school satisfaction. Two variables addressing school satisfaction were also analyzed to determine specific factors that could impact school satisfaction: satisfaction with schools and satisfaction with discipline. A possible remaining source of bias is that students with autism tend to display unwanted behaviors more frequently than their typically developing counterparts, which could lend to a negative view of school satisfaction depending on how the school addresses these behaviors, as well as how they communicate with families regarding their child's progress. The sample size is limited to a total of 141 randomly selected participants including a total of 68 students with autism and a total of 73 nondisabled peers. While the sample size is small, it is representative due to its even comparison of both groups.

\section{Results and Discussion}

The current investigation examines two variables for inclusion in additional analyses: autism (E46/H29) and child sex (E60/H43). Grade level spans grades 3-5. The data 
analysis is based on $n=141$ participants. Table 1 presents frequencies for autism and student gender.

Table 1: Frequency of Race and Disability Status

\begin{tabular}{lccc}
\hline Disability Status & Male & Female & Total \\
\hline Autism & 53 & 15 & 68 \\
\hline No Disability & 45 & 28 & 73 \\
\hline
\end{tabular}

The results from the crosstabulation comparing students with autism and gender indicate that there are more males with autism (53) then females with autism (15). Additionally, there are more males without a disability (45) than females (28). Overall, more males than females were included in the sample population.

The frequencies for child race and child disability status are reported in Table 2.

Table 2: Frequency of Race and Disability Status

\begin{tabular}{lcc}
\hline Race & Peers with Autism & Typically Developing Peers \\
\hline White, Non-Hispanic & 39 & 46 \\
\hline Black, Non-Hispanic & 4 & 5 \\
\hline Hispanic & 15 & 15 \\
\hline All Other Races Multiple Races, Non-Hispanic & 10 & 7 \\
\hline
\end{tabular}

Table 2 indicates that most students with autism are identified as being White, NonHispanic, as is the total sample. Basic descriptive statistics regarding research question indicate that the average times contacted about a problem at school was $\mathrm{M}=1.06$ (sd = 2.31). An Independent Sample $t$ Test was conducted. The results of this analysis indicate that there are significant differences in times contacted about behavior problems for students with autism $(M=1.50)$ and students without autism $(M=.64)$ students, $t(86.91)$ $=2.18, p=.032$. An Independent Samples $t$ test was used to determine the significance between the variables concerning times contacted about behavior problems. The Levene's Test of Homogeneity of Variance indicates that this assumption is tenable, $F(139)=9.300, p=.003$.

The frequencies for the variable satisfaction with schools from research question two are provided in Table 3.

Table 3: Satisfaction with Schools Students with Autism and Typically Developing Peers

\begin{tabular}{lcccc}
\hline Variable & $\begin{array}{c}\text { Very } \\
\text { Satisfied }\end{array}$ & $\begin{array}{c}\text { Somewhat } \\
\text { Satisfied }\end{array}$ & $\begin{array}{c}\text { Somewhat } \\
\text { Dissatisfied }\end{array}$ & $\begin{array}{c}\text { Very } \\
\text { Dissatisfied }\end{array}$ \\
\hline Autism & 40 & 21 & 7 & 0 \\
\hline Does Not Have a Disability & 54 & 16 & 3 & 0 \\
\hline
\end{tabular}

Results of the Pearson's Chi Square indicate that there is not a statistically significant difference in the level of satisfaction with school and students with autism compared to typically developing peers, $\chi^{2}(2)=4.19, p=.123$. The frequencies for satisfaction with discipline for students with autism are provided in Table 4. 

WITH AUTISM SPECTRUM DISORDER AND TYPICALLY DEVELOPING PEERS

\begin{tabular}{lcccc}
\hline Table 4: Satisfaction with Discipline for Students with Autism and Typically Developing Peers \\
\hline Variable & $\begin{array}{c}\text { Very } \\
\text { Satisfied }\end{array}$ & $\begin{array}{c}\text { Somewhat } \\
\text { Satisfied }\end{array}$ & $\begin{array}{c}\text { Somewhat } \\
\text { Dissatisfied }\end{array}$ & $\begin{array}{c}\text { Very } \\
\text { Dissatisfied }\end{array}$ \\
\hline Autism & 43 & 16 & 5 & 4 \\
\hline Does Not Have a Disability & 53 & 16 & 2 & 2 \\
\hline
\end{tabular}

Results of the Pearson's Chi Square indicate that there is not a statistically significant difference in the level of satisfaction with discipline and students with autism compared to typically developing peers, $\chi^{2}(3)=2.82, p=.420$.

When determining if there were differences in school satisfaction and satisfaction for students with autism compared to typically developing peers, frequency tests were run for both of the variables compared to the two groups (i.e., school satisfaction levels for students with autism and typically developing peers, and satisfaction with discipline for students with autism and typically developing peers). Results from the Pearson's Chi Square test that analyzed levels of school satisfaction and satisfaction of discipline between the two groups indicated that there were not significant differences for both variables for both groups. Reasons for these results are possibly due to response bias. Additionally, this could depend on factors such as level of communication between schools and families, which parents of students with autism have expressed as being particularly important (Slade et al., 2018). The participants of this study may receive a satisfactory level of communication leading to more satisfaction with schools overall. While it is difficult to know why the parents indicated their level of satisfaction, but it is clear from the extant research that parents and teachers satisfaction is important to the cohesiveness of the child's education (Billingsley \& Bettini, 2019). More work needs to be done to ensure that special education teachers and parents are having their needs met in addition to the child with special needs (Gershwin Mueller, Massafra, Robinson, \& Peterson, 2019). Enhancing collaborations between all stakeholders can lead to greater parent satisfaction and teacher longevity in the important work of educating the child with special needs (Bricker, Felimban, Lin, Stegenga, \& Storie, 2020).

\section{Conclusion}

Overall conclusions indicate there are significant differences between the number of times contacted about behavior problems between students with autism and typically developing peers. However, there were no significant differences between levels of school satisfaction and satisfaction with discipline for students with autism and typically developing peers. These results could be due to several factors, including school communication and higher incidences of behavior problems for students with autism. Implications for this study show that further research regarding school satisfaction is needed to determine specific factors that influenced the participants' survey responses.

Limitations of this study include a small sample size, which may not fully represent both groups. However, the small sample size was based on a random sampling of the available data. Additionally, there were a high number of male participants, which 
may have been an overrepresentation of the male student population and an underrepresentation of the female student population. Recommendations based on the analysis include using a larger sample size in further research, as well as analyzing other possible factors that potentially influenced the outcomes of this study, such as school communication, specific behaviors, grade levels, home issues, etc. Additional variables might include information about prior experiences and satisfaction with schools. Identifying and analyzing these specific factors in addition to utilizing a larger sample size would strengthen the results of this research. Future questions might examine how a larger sample size effects this information.

\section{About the Authors}

Gianna DeToro, M.S. Ed. earned her bachelor's degree in early childhood education and special education from Youngstown State University in 2015. She continued her education at YSU in the field of school psychology where she earned her Master of Education in 2020. She is currently working on obtaining her educational specialist degree at YSU. Gianna DeToro is serving a practicum student at Hubbard Exempted School District in Hubbard Ohio.

Catherine Miller Knowlden received her M.Ed in Intervention Services from Youngstown State University and is currently pursuing her Ed.S in School Psychology. Catherine has worked as an Intervention Specialist for students in the mild/moderate range for the last six years at Salem Junior High, located in Salem, Ohio, where she has focused on providing intervention and support for students with special needs and for at-risk students specifically in English Language Arts. Catherine is currently a member of the Ohio School Psychologists Association and is an active member of the Honor Society of Phi Kappa Phi for her academic achievements. She aspires to use her skills to support students holistically so that they can reach their fullest potential.

Karen H. Larwin, PhD. earned her Ph.D. from Kent State University in Evaluation, Measurement, and Applied Statistics in 2007. She currently serves as an Associate Professor at Youngstown State University in the Counseling, School Psychology, and Leadership department. For more than a decade, Dr. Larwin has participated as the evaluator on multiple federal and state-wide grant-supported projects focusing on improving the health, education, and quality of life for children and adults. She currently serves as an evaluator for Ohio Commission on Minority Health, the Higher Learning Commission, and CAEP. Her teaching has focused on empowering master's level and doctoral students to use research in their daily work arenas. Her methodological research focuses on meta-analytic procedures and structural equation modeling applications. Dr. Larwin is credited for developing a statistical application, SIR-SEM, that is used for systematic item elimination within structural equation modeling. In addition to her teaching, community service, and scholarship, Dr. Larwin serves as a chair for the American Evaluation Association Quantitative Methods section, and as the chair of the YSU Institutional Review Board. 


\section{References}

Ashburner, J., Ziviani, J., \& Rodger, S. (2010). Surviving in the mainstream: Capacity of children with autism spectrum disorders to perform academically and regulate their emotions and behavior at school. Research in Autism Spectrum Disorders, $4(1), 18-27$.

Billingsley, B., \& Bettini, E. (2019). Special education teacher attrition and retention: A review of the literature. Review of Educational Research. 89(5). 697-744.

Boonen, H., Maljaars, J., Lambrechts, G., Zink, I., Van Leeuwen, K., \& Noens, I. (2014). Behavior problems among school-aged children with autism spectrum disorder: Associations with children's communication difficulties and parenting behaviors. Research in Autism Spectrum Disorders, 8(6), 716-725.

Bricker, D. D., Felimban, H. S., Lin, F. Y., Stegenga, S. M., \& Storie, S. O. (2020). A proposed framework for enhancing collaboration in early intervention/early childhood education. Topic in Early Childhood Special Education, 1-13

Gershwin Muller, T., Massafra, A., Robinson, J., \& Peterson, L. (2019). Simulated individualized education program meetings: Valuable pedagogy within a preservice teacher educator program. Teacher Education and Special Education, 42(3), 209-226.

Munkhaugen, E. K., Torske, T., Gjevik, E., Nærland, T., Pripp, A. H., \& Diseth, T. H. (2019). Individual characteristics of students with autism spectrum disorders and school refusal behavior. Autism, 23(2), 413-423. doi:10.1177/1362361317748619

Slade, N., Eisenhower, A., Carter, A. S., \& Blacher, J. (2018). Satisfaction with Individualized Education Programs Among Parents of Young Children With ASD. Exceptional Children, 84(3), 242-260. doi:10.1177/0014402917742923

Starr, Elizabeth M., and Janis B. Foy. "In parents' voices: The education of children with autism spectrum disorders." Remedial and Special Education 33.4 (2012): 207-216.

Strain, P. S., Wilson, K., \& Dunlap, G. (2011). Prevent-teach-reinforce: Addressing problem behaviors of students with autism in general education classrooms. Behavioral Disorders, 36(3), 160-171.

Whitaker, P. (2007). Provision for youngsters with autistic spectrum disorders in mainstream schools: what parents say - and what parents want. British Journal of Special Education, 34(3), 170-178. doi:10.1111/J.1467-8578.2007.00473X

Zablotsky, B., Boswell, K., \& Smith, C. (2012). An evaluation of school involvement and satisfaction of parents of children with autism spectrum disorders. American Journal on Intellectual and Developmental Disabilities, 117(4), 316-330. 
Authors will retain the copyright of their published articles agreeing that a Creative Commons Attribution 4.0 International License (CC BY 4.0) terms will be applied to their work. Under the terms of this license, no permission is required from the author(s) or publisher for members of the community to copy, distribute, transmit or adapt the article content, providing a proper, prominent and unambiguous attribution to the authors in a manner that makes clear that the materials are being reused under permission of a Creative Commons License. Views, opinions and conclusions expressed in this research article are views, opinions and conclusions of the author(s). Open Access Publishing Group and European Journal of Special Education Research shall not be responsible or answerable for any loss, damage or liability caused in relation to/arising out of conflict of interests, copyright violations and inappropriate or inaccurate use of any kind content related or integrated on the research work. All the published works are meeting the Open Access Publishing requirements and can be freely accessed, shared, modified, distributed and used in educational, commercial and non-commercial purposes under a Creative Commons Attribution 4.0 International License (CC BY 4.0). 